\title{
HOLLYWOOD EM SALA DE AULA: REFLEXÕES SOBRE CINEMA E ENSINO DE HISTÓRIA
}

\section{FLÁVIO VILAS-BÔAS TROVÃO*}

Resumo: O uso do cinema como recurso didático-pedagógico ou ilustrativo nas aulas de história não é uma novidade, é aplicado desde o início do século XX, concomitante ao desenvolvimento da própria história do cinema. O fato é que cada vez mais esse uso tem se direcionado para uma cinematografia específica: a hollywoodiana, graças a sua força de penetração cultural. Analisamos as implicações políticas e estéticas do uso desses materiais nas aulas de história, com destaque para o papel dos jovens diante de uma cultura midiática que se torna, cada vez mais, homogênea e globalizada.

Palavras-chave: História. Ensino. Cinema.

\section{Hollywood in the classroom: reflections about cinema and the history teaching}

Abstract: The use of cinema as didactic and pedagogical or illustrative resource in history classes is not new, is applied from the beginning of the twentieth century, concurrent with the development of the history of cinema. The fact is the increasingly this use has been directed to a specific cinematography: the Hollywood, due to its cultural penetration force. We analyze the political and aesthetic implications of the use of these materials in History Classes, highlighting the role of the youth facing a media culture that becomes increasingly homogeneous and globalized.

Keywords: History. Education. Cinema.

\section{O cinema nas aulas de história: uma questão secular.}

A história do uso do cinema como recurso educacional é concomitante à própria história do cinema em si: desde os primeiros anos do século XX membros da nascente indústria fílmica, bem como intelectuais e educadores, percebiam na capacidade narrativa do cinema e sua atração sobre as plateias uma poderosa ferramenta educativa.

Walter Benjamin, em seu conhecido ensaio onde analisa as "obras de arte reprodutíveis" vê no cinema uma arte possível de educar as massas à medida que registra a sociedade que o produz: “o que caracteriza o filme não é só a forma como o homem se apresenta perante o equipamento de registro, mas também a forma como, com a ajuda daquele, reproduz o seu meio ambiente" (Benjamin, 1992, p. 102).

\footnotetext{
* Doutor em História Social pela Universidade de São Paulo (USP). Realiza atualmente estágio pósdoutoral na mesma universidade. É professor da Universidade Federal do Mato Grosso (UFMT/ Campus de Rondonópolis). E-mail: flaviotrovao@hotmail.com
} 
No Brasil a ideia de usar o cinema como recurso didático também remonta ao início do século XX, como demonstra Circe Bittencourt.

Introduzir as imagens cinematográficas como material didático no ensino de História não é novidade. Jonathas Serrano, professor do Colégio Pedro II e conhecido autor de livros didáticos, procurava desde 1912 incentivar seus colegas a recorrer a filmes de ficção ou documentários para facilitar o aprendizado da disciplina (Bittencourt, 2011, p. 371).

Nesse sentido o Cinema aparece, portanto, como instrumento e recurso utilizado pelo professor em sala de aula, seja de quem já está na lida ou daqueles que estão por ingressar. Para Kátia Abud, a didática da História tem sua singularidade referenciada na medida em que essa "ultrapassa a simples transmissão de saberes, para se tornar um campo de conhecimento no qual se imbricam a História ciência e a História escolar, cada uma com elementos próprios" (Abud et al., 2010, p. IX).

Segundo a autora,

Os filmes, à semelhança do que ocorre com o conhecimento histórico, são produzidos com base em processos de pluralização de sentidos ou verdades. Apesar das particularidades e especificidades de cada um - dos filmes e do conhecimento histórico -, incluindo seus métodos de trabalho, ambos são construções mentais que precisam ser pensadas e trabalhadas intensamente (Abud et al., 2010, p. 165).

Nesse contexto percebe-se que os professores de História têm se utilizado do cinema como recurso para suas aulas ao longo de todo o século $\mathrm{XX}$, principalmente com a difusão dos aparelhos de Super 8 a partir dos anos 1960 ou do videocassete no final da década de 1970. Dentre a cinematografia projetada em sala de aula, a partir das mais diversas temáticas, a maioria é ou de origem estadunidense ou brasileira contemporânea (chamado "Cinema da Retomada"). ${ }^{1}$ O que propomos problematizar é

\footnotetext{
${ }^{1}$ O cinema brasileiro produzido ao longo da década de 1990 teve na obra da diretora Carla Camurati seu marco. O filme "Carlota Joaquina, a Princesa do Brasil" (1995) atraiu uma parcela considerável de público brasileiro para as salas de cinema para assistir a um filme nacional. O sucesso dessa obra acabou por se tornar a referência de uma "retomada" do cinema brasileiro, agora não mais pautado nos princípios políticos e estéticos do Cinema Novo, tampouco das chanchadas dos anos 1970 e 1980 (da chamada "Boca do Lixo"). Sobre o tema ver: MARSON, M. 2006. O Cinema da Retomada: Estado e cinema no Brasil, da dissolução da EMBRAFILME à criação da ANCINE. Campinas, Dissertação de Mestrado, Universidade Estadual de Campinas, 203 p.
} 
que o uso desses materiais, descontextualizados de suas relações históricas de produção bem como das questões políticas e ideológicas que carregam, pode corroborar para uma visão acrítica tanto histórica quanto cultural, em especial, no que se refere à cultura da mídia (Cf. Kellner, 2001).

\section{A hegemonia do cinema hollywoodiano.}

Em seu nascimento no final do século XIX e início do século XX, o cinema se apresentava como um experimento técnico-científico e Thomas Jefferson, o precursor do cinema nos Estados Unidos, registrou o equipamento cinematográfico (projetor) como sua propriedade intelectual e recebia por seu uso naquele país. Com o tempo, porém, a história contada nos filmes, a fábula (ou trama), ganhou tanta importância que cada vez mais o cinema passou ser visto como uma diversão (Shatz,1991).

Já nos anos 1920 os filmes se tornaram um importante produto industrial que aferia muitos lucros para seus produtores. Foi nessa época que homens de negócios se uniram para formar grandes estúdios cinematográficos nos Estados Unidos. Utilizando o mesmo modelo de produção da grande indústria, o fordismo (ou seja, a produção feita em série e dividida em rígidas e controladas etapas), os estúdios passaram a produzir muitos filmes, mantendo uma ampla rede de exibição, as salas de cinema. Eram nas chamadas bilheterias dessas salas que o lucro aparecia, com a venda de milhares de ingressos para um mesmo filme. Assim, quanto mais filmes, mais público pagante e, portanto, mais lucro.

Nos Estados Unidos, com a popularização da televisão em fins dos anos 1940 e início dos 1950 as salas de cinema perderam muitos espectadores adultos que, agora, podiam assistir às películas clássicas e novas no conforto das salas de suas casas. Para poder concorrer com o novo aparelho eletrônico, os estúdios hollywoodianos tentaram de tudo: criaram filmes que necessitavam de três projetores ao mesmo tempo e que criavam a sensação de uma visão de 180 graus, como também os primeiros filmes em três dimensões (3D), hoje amplamente utilizado para combater a pirataria, ou seja, a cópia ilegal dos filmes. ${ }^{2}$ As palavras de um dos proprietários dos estúdios MGM re-

\footnotetext{
2 O primeiro filme 3D da história do cinema foi "Disque M para matar" de Alfred Hitchcock, nos anos 1950.
} 
trata bem esse momento, ao questionar "por que as pessoas pagariam para assistir a filmes ruins no cinema se, agora, poderiam fazê-lo gratuitamente em suas casas?"3

Foi somente em meados da década de 1970 que o cinema americano voltou a ter altos lucros e salas lotadas de espectadores, agora em sua maioria formada por adolescentes de classe média. Isso porque os filmes dessa época contavam histórias simples - como o ataque de um tubarão em uma praia - porém com uma riqueza de efeitos especiais, uso de robôs e grandes efeitos sonoros. Eram os filmes de "espetacularidade", dos quais diretores como Georges Lucas e Steven Spielberg são os principais expoentes.

Nesse momento, no Brasil, a ditadura militar reprimia e censurava filmes mais politizados e de temática adulta e privilegiavam um estilo de comédia que já era conhecido desde os anos 1950 como "chanchada". Em algumas versões, as chanchadas passavam a ter um caráter erótico, atraindo o público adulto masculino para as salas de cinema, nas chamadas "pornochanchadas". Essa diferença entre as duas indústrias cinematográficas nesse momento histórico - nos Estados Unidos atraindo adolescentes com efeitos especiais visualmente grandiosos e a indústria cinematográfica brasileira atraindo um pequeno público adulto e sob censura - é um dos fatores que nos permite compreender a ampliação da exibição de filmes estadunidenses no circuito cinematográfico nacional a partir de finais dos anos 1960.

Com o processo de globalização da economia ampliou-se, ainda mais, a penetração da cultura midiática estadunidense no Brasil e no mundo como um todo. As redes de televisão a cabo divulgam um vasto material midiático produzido pelos estúdios hollywoodianos. Fenômenos multimidiáticos como a "Saga Crepúsculo" permitem pensarmos uma cultura que se constrói muito em função das novas relações de poder que os conglomerados midiáticos passaram a ter no último quartel do século XX. Livros de grande alcance entre o público jovem tornam-se histórias propícias para séries de filmes, que por sua vez darão origens a outros produtos midiáticos e culturais: comercialização de trilhas sonoras, clipes musicais, games, brinquedos, sítios eletrônicos,

\footnotetext{
${ }^{3}$ Outro fator que intensificou a crise do cinema nos anos 1950, nos Estados Unidos, foi uma lei federal que acabou por desmembrar o sistema de produção, distribuição e exibição que era monopolizado pelos estúdios. Perdendo o braço da exibição, ou seja, o controle direto das bilheterias, as grandes corporações viram parte de seus lucros diminuírem ao longo daquela década. Ver: Bergan, 2007, p.44-54.
} 
parque de diversões, entre outros. ${ }^{4}$

Dessa forma, desde então, o filme estadunidense goza de um privilégio de mercado em nosso país difícil de ser revertido. Assim, a maior parte dos então jovens e adolescentes dos anos 1970 e 1980 cresceram tomando a experiência das indústrias hollywoodianas como sua principal referência cinematográfica, quando não a única. Assim o cinema americano é visto, muitas vezes, como superior e melhor que o nacional, limitando as possibilidades de conhecer a história e cinematografias produzidas em outros países, inclusive no Brasil.

Segundo Marcos Napolitano

Estes problemas de distribuição, no Brasil, ficam ainda mais graves quando percebemos uma concentração das salas de exibição nas grandes metrópoles e, nestas, em shoppings centers. Existem milhares de cidades no Brasil que não têm sequer uma sala de cinema. Aliado ao fato de que mais de $90 \%$ das locadoras não têm catálogo muito variado que ofereçam filmes antigos ou filmes importantes, mas pouco conhecidos, limitando-se aos sucessos do momento, percebese por que a cultura cinematográfica do cidadão médio está cada vez mais restrita a um tipo de cinema, o comercial americano (Napolitano, 2013, p. 61).

Nesse contexto o que pode ser comprometedor é que nosso olhar estético, nossa concepção do que é um "bom filme" passe a ser somente aqueles que são executados dentro dos padrões hollywoodianos de produção, ou seja, com personagens definidos, narrativa cronológica, final feliz, entre outros elementos que compõem essas narrativas. ${ }^{5}$

Isso faz com que outras produções que não sigam essa "fórmula", sejam consideradas "ruins" ou "sem sentido". Mas nem toda experiência cinematográfica têm de ser entendida racional e linearmente. Por vezes, existem obras e diretores que que-

\footnotetext{
${ }^{4}$ Para compreender o processo de fusão dos conglomerados midiáticos na era da globalização e seus desdobramentos, ver: SILVA, T. G. 2014. Dirigido por Martin Scorsese: um estudo comparativo de Taxi Driver, Os Infiltrados e seus contextos de produção. Rio de Janeiro, RJ, Dissertação de Mestrado, Universidade Federal do Rio de Janeiro. 212p.

5 "O filme hollywoodiano clássico apresenta indivíduos definidos, emprenhados em resolver um problema evidente ou atingir objetivos específicos. Nessa busca, os personagens entram em conflito com outros personagens ou com circunstâncias externas. A história finaliza com uma vitória ou derrota decisivas, a resolução dos problemas e a clara consecução ou não-consecução dos objetivos. O principal agente causal é, portanto, o personagem, um indivíduo distinto dotado de um conjunto evidente e consistente de traços, qualidades e comportamentos" (Bordwell, 2004, 279).
} 
rem, em um primeiro momento, nos desconcertar, nos tirar da posição passiva de consumo da imagem e nos fazer refletir: o que tais imagens representam? Como se dá a narrativa dessa fábula? Por que o filme não tem fim (como se, para fazer sentido, tudo tivesse de ser explicado)?

A escola é uma instituição onde, entre outros objetivos específicos, devem-se criar as condições para a ampliação da cultura das pessoas que vivem em seu meio. Isso quer dizer que professores, estudantes, funcionários, famílias, enfim, todos que estão envolvidos no sistema educacional, devem crescer culturalmente à medida que trabalhem e estejam envolvidos com o universo escolar. Mas como é possível ampliar a cultura cinematográfica na escola?

Segundo Marcos Napolitano, "a escola pode dar uma contribuição para a diversificação da cultura audiovisual ao trabalhar com filmes de origens, épocas e linguagens diversas, apesar das dificuldades de acesso." (Napolitano, 2013, p. 64).

Porém, para que essa experiência tenha também um efeito pedagógico, além de estético e cultural, cabe, ainda, uma sugestão: a ampliação e conhecimento da linguagem cinematográfica. Assim como o professor de matemática precisa compreender a linguagem algébrica, o professor de geografia compreender a linguagem cartográfica, o uso do cinema terá amplos significados e usos didáticos à medida que nós, professores, estudarmos e conhecermos melhor a linguagem que o cinema se utiliza para contar as fábulas nos filmes. Aí então, tal qual o matemático lê a fórmula e o geógrafo o mapa, pode-se ler o filme, ou seja, compreendê-lo em suas estruturas constituintes.

\section{A cultura da mídia e as juventudes.}

Nesse contexto que estamos esboçando os jovens têm sido o público alvo preferencial das indústrias cinematográficas hollywoodianas desde os anos 1970 e, atualmente, seus produtos extrapolam para vários derivados como games, dvds, brinquedos, livros, entre outros. Cinema, televisão, rádio, internet, smart phones, tablets são tecnologias e meios que aproximam e identificam a cultura midiática, tal qual a caracteriza Douglas Kellner, as quais as pessoas (sobretudo as mais jovens) passam a utilizar, consumir e operar para se comunicar, divertir, criar e, também, aprender e ensinar. Porém, ter acesso a essas tecnologias não é o suficiente, visto que é importante a pos- 
tura crítica diante de seus desenvolvimentos.

Para Kellner,

... a obtenção de informações críticas sobre a mídia constitui uma fonte importante de aprendizado sobre o modo de conviver com esse ambiente cultural sedutor. Aprendendo como ler e criticar a mídia, resistindo a sua manipulação, os indivíduos poderão fortalecer-se em relação à mídia e à cultura dominante. Poderão aumentar sua autonomia diante da cultura da mídia e adquirir mais poder sobre o meio cultural, bem como os necessários conhecimentos para produzir novas formas de cultura (Kellner, 2001, p. 10).

Caracterizada como fenômeno desde a segunda metade do século XX, a juventude vem se configurando mais que uma faixa etária em um público complexo e diverso na sociedade de consumo. Para tanto, a tendência mercadológica procura aproximar e caracterizar os fenômenos da juventude como fenômenos de massa, padronizando e simplificando sua diversidade. ${ }^{6}$

Os significados históricos dados a cada "geração de jovens" reforçam os padrões de juventudes que se desejavam em cada época: nos anos 1950 vista como alienada, nos anos 1960 como oprimida, nos anos 1970 como rebelde, nos anos 1980 como perdida, entre outras caracterizações.

No período do pós-guerra, quando a ampliação da permanência de jovens nas instituições educativas e a aparição do 'consumidor adolescente' consagram o nascimento de uma nova classe de idade nos países industrializados, as teorias sobre a existência de uma 'cultura juvenil' autônoma e interclassista se generalizam e passam a ter legitimidade científica (Caccia-Bava, 2004, p. 308).

Ainda que a grande mídia como o cinema e a televisão enfatizem os aspectos "comuns" que determinadas gerações de jovens possam ter tido, os estudos ligados à sociologia da juventude apontam a necessidade de compreender não os aspectos de "uma determinada geração", mas sim a pluralidade de sujeitos que compõem determinadas cortes juvenis. Dessa forma, não usaríamos mais a ideia de uma geração pa-

\footnotetext{
${ }^{6}$ Segundo Rossana Reguillo, "[...] la juventude, como hoy la conocemos, es propriamente uma invención de la pós-guerra que hizo posible el surgemiento de um nuevo orden internacional que conformo uma geografia política en la que los vencedores accedían a inéditos estándares de vida e imponían sus estilos y valores." (p. 49). Porém, autores como Jon Savage argumentam que a "invenção da juventude" é anterior, ainda no século XIX.
} 
drão, mas sim, de juventudes, no plural, representando a pluralidade dos sujeitos e situações que compõem a vida dos jovens na atualidade.

Ao envolver-me neste desafio senti a necessidade de olhar a juventude não apenas com um conjunto social cujo principal atributo é o de ser constituído por indivíduos pertencentes a uma dada fase da vida mas também como conjunto social com atributos sociais que diferenciam os jovens; isto é, vi-me na necessidade de passar do campo semântico da juventude que a toma como unidade para o campo semântico que a toma como diversidade (Pais, 1993, p. 36).

O fato é que os fenômenos juvenis vêm aglutinando uma gama diversificada de experiências sociais, sobretudo, as experiências midiáticas. Sejam como consumidores ou produtores da tecnologia, os jovens se aproximam das mídias e tecnologia em uma espécie de "simbiose", onde só se pode acessar uma através ou juntamente com a outra. As mídias atuais são mais acessíveis aos jovens e, cada vez mais, ser jovem significa ter acesso às (multi)mídias e tecnologias contemporâneas. Fenômenos culturais contemporâneos, como as redes sociais eletrônicas ${ }^{7}$ encontram nos jovens tanto o público consumidor quanto o criador e difusor dessas mesmas redes.

Um mundo altamente tecnológico encontra no processo educativo sua base de sustentação, mas se realizado sem a devida crítica e apenas em função das necessidades mercadológicas, a educação pode se tornar alienante. O mundo comunicacional, cada vez mais pautado na imagem, exige uma leitura crítica, como aponta Baudrillard (1981), para além dos "simulacros e das simulações."

Compreendida como "sociedade do conhecimento", conforme Edgar Morin, a educação para a autonomia dos sujeitos deve se direcionar para a complexidade da vida na contemporaneidade. Nesse sentido o saber deve extrapolar os limites constituídos desde o século XIX do espaço escolar e utilizar-se das mais diversas plataformas tecnológicas como meio e objeto. Assim, mais do que aprender técnicas e métodos, visamos problematizar a própria razão do saber e do aprender, compreendendo criticamente as mídias, seu universo tecnológico e linguístico.

Segundo Morin,

\footnotetext{
${ }^{7}$ Usamos o termo "redes sociais eletrônicas" visto a existência de estudos, como os de Robert Darnton, que apontam a existência de redes de comunicação desde o Ancién Régimen, ou seja, o século XVIII. A característica dessas redes contemporâneas está muito mais no fato de se darem de forma eletrônica e simultânea. Ver: Darnton, 2014.
} 
A educação atual proporciona conhecimentos sem ensinar o que é o conhecimento. Não se preocupa em conhecer o que é conhecer, quer dizer, não estuda os dispositivos cognitivos, suas dificuldades, suas debilidades, nem suas propensões ao erro, à ilusão. [...] Um conhecimento é pertinente se sabe situar-se em seu contexto, e mais além, no conjunto com o qual está relacionado (Morin, 2011, p. 150-151).

A necessidade, em nosso entendimento, é de avançarmos o olhar para outro modo de ver as representações e discursos da mídia, compreendendo-os, também, em suas linguagens constituintes. Portanto, problematizar as imagens tradicionais especialmente aquelas realizadas pelo cinema hollywoodiano, pode ser um caminho de emancipação e autonomia diante da cultura da mídia.

Como já firmamos, a linguagem cinematográfica, assim como qualquer linguagem, leva tempo para ser compreendida, assimilada. O importante é que o educador que deseja desenvolver uma atividade em sala de aula tendo o material fílmico como base, para além da interpretação da fábula, comece a perceber e aprofundar sua própria leitura fílmica. Assim como ler um texto ou um livro vão se tornando mais familiares e prazerosos com o hábito, a leitura fílmica também vai se tornando uma prática tanto do educador quanto dos estudantes, desde que sejam ensinados a fazê-lo. ${ }^{8} \mathrm{E}$ aqui reiteramos que a escola é um espaço onde esses saberes também devem ser ensinados, seja de forma multidisciplinar ou ainda dentro da especificidade de cada disciplina escolar.

\section{O que pensam os historiadores sobre o Cinema Hollywoodiano?}

Ao usarmos os filmes hollywoodianos em sala de aula sem considerar as questões envolvendo a cultura da mídia e suas relações com as juventudes atuais, corre-se o risco de tratar o filme como um produto isento de ideologias, interesses e relações de poder. Por isso o uso do cinema na aula de História deve levar em conta também as reflexões dos historiadores sobre o próprio cinema americano.

No ensaio intitulado, "O cinema: arma americana para a Guerra Fria", Pierre Sorlin demonstra historicamente como o cinema foi utilizado enquanto artifício bélico do governo estadunidense durante o conflito ideológico contra a União Soviética (Sor-

\footnotetext{
${ }^{8}$ Sobre os métodos de leitura fílmica e seu uso na educação ver: Trovão, 2015.
} 
lin, 1998).

O autor afirma que nos anos da Guerra Fria (1947-1991), o mais importante para as potências mundiais (na época os Estados Unidos e a União Soviética) era a manutenção de um arsenal bélico que ameaçasse o oponente e mostrasse ao resto do mundo seu poder, porém, mantendo latente a possibilidade de bombardear diretamente o outro. Sorlin argumenta, ainda, que na segunda metade do século XX o cinema feito em Hollywood foi, ao mesmo tempo, produtor e difusor de imagens sobre o perigo representado pelo sistema comunista, bem como, da supremacia do sistema liberal estadunidense. Partindo da análise de cine jornais e longas-metragens, o autor demonstra o caráter político-propagandístico que o cinema adquiriu nos Estados Unidos a partir da Segunda Guerra Mundial. E quando usamos esses materiais em sala de aula, seja como ilustração, documento ou problematização dos temas da História, devemos estar atentos a esses aspectos da obra cinematográfica em uso.

O filme operando como forma de propaganda política não é exclusividade da cinematografia estadunidense; nos escritos de Marc Ferro já se apontava para essa possibilidade de interpretação. Porém, para Pierre Sorlin, “a propaganda, arma clássica em qualquer conflito, teve um uso particular no confronto entre os americanos e soviéticos", pois nesse caso, "o cinema não se restringiu a defender o modelo capitalista ocidental para os povos do Ocidente, mas sim, tentou seduzir o inimigo." (Sorlin, p.380).

O autor demonstra sua tese na análise de filmes de longa-metragem (feature films), documentários e músicas que foram difundidos pela emissora de televisão da Berlim Ocidental e que eram também recebidos no lado Oriental da cidade. Eles tinham o claro objetivo de retratar aos alemães o quão diferente eram os modos capitalista e comunista presentes na mesma cidade, no mesmo povo, e assegurar a supremacia do modelo capitalista. Nesse sentido, o filme não foi usado da mesma forma como o foi no stalinismo ou no nazismo, ou seja, difundindo as ideias favoráveis aos regimes em questão entre o seu próprio povo. Parte do cinema feito em Hollywood entre os anos 1950 e 1980 constituiu-se como "arma" de guerra, um artifício bélico para destruir o outro, o inimigo, em seu próprio território, assim como um míssil.

Pierre Sorlin destaca que 
Historiadores interessados em cinema consideram os filmes como fontes históricas primárias, como um tipo de documento da evolução das mentalidades e comportamentos de uma era. Eles são também uma potente arma que auxiliou a controlar e "induzir" a opinião pública ocidental durante os momentos mais dramáticos da Guerra Fria. Os filmes auxiliaram a atrair o a opinião ocidental a resistir à capacidade de sedução do mundo soviético (Sorlin, p. 381).

O contexto histórico do momento da produção de um filme também se faz presente na forma como a narrativa fílmica se constrói e, no período da Guerra Fria, tal contexto foi tão intenso que marcou um grande número de obras cinematográficas por um período considerável de tempo. ${ }^{9}$

K.R.M. Short foi diretor da Escola de Comunicação da Universidade de Houston onde lecionava a disciplina de História. Suas pesquisas entendem a relação entre Cinema e História a partir da especificidade do filme Hollywoodiano. No ensaio de introdução de sua obra Feature films as History, Short afirma que o impacto da comunicação de massas que ocorreu primeiramente na Europa e na América do Norte e, mais tarde, no restante do mundo, é o fato mais significante do século XX. (Short, 1981, p. 16)

Entre outros problemas, o autor aponta a questão da censura aplicada aos filmes, presente nas versões comerciais editadas pelos estúdios e, muitas vezes, em desacordo com aquela pensada e realizada pelos diretores. ${ }^{10}$ Além disso, Short sugere que sejam utilizados para análises fílmicas, outros materiais produzidos pela indústria hollywoodiana, como cartazes de divulgação, entrevistas, críticas, entre outros. Concluindo o ensaio, o autor sugere aos historiadores abordar os filmes ficcionais de longas metragens como produtos de uma indústria e, dessa forma, envolvidos por interesses políticos, sociais e econômicos. Afirma também que tais filmes, apesar de baseados em roteiros ficcionais, refletem realidades históricas desejáveis por parte dessa indústria.

\footnotetext{
${ }^{9}$ Ver: Trovão, 2013.

${ }^{10}$ Sobre essa questão das edições realizadas com interesse meramente comercial e, na maior parte das vezes, em desacordo, quando não sob o total desconhecimento por parte dos diretores, há dois filmes do cineasta espanhol Carlos Benpar, a saber: Cineastas contra magnats (2005) e Cineastas en Accion (2005). Ambos foram exibidos na Mostra de Cinema Espanhol Histórico e Contemporâneo realizado na Cinemateca Brasileira, em São Paulo, em maio de 2007. Neles, diretores como Woody Allen, Bernardo Bertolucci, Jean-Luc Godard, entre outros, mostram os absurdos realizados pela indústria, em filmes tanto de sua autoria quanto de outros colegas, com o objetivo de editar os originais para exibição em televisão ou na venda dos títulos sob outros suportes como VHS e DVD.
} 
Em posição mais radical sobre a relação História e Cinema, o historiador e roteirista Robert A. Rosenstone defende, no início de seu livro Revisioning History "a premissa: os meios imagéticos são legítimos para se fazer História" (Rosenstone, 1995, p. 4).

Canadense radicado nos Estados Unidos, Rosenstone, ataca o predomínio do meio escrito como forma de se fazer História. Nesse sentido, o cinema deixa de ser um objeto de análise distante para se tornar meio para o historiador produzir o discurso histórico. Com isso, o domínio da linguagem cinematográfica se ressignifica, tornando possível, ao historiador, produzir o que o autor chamou de seriously historical films. A diferença entre os filmes comerciais e os "filmes históricos sérios" reside no objetivo de suas produções: menos entreter e divertir e mais representar o passado sob a forma de imagens. ${ }^{11}$ Esses materiais constituem o que o autor denomina o New History Film, ou o Novo Filme Histórico.

Robert Rosenstone defende a ideia de que os filmes históricos, em especial, os de caráter dramático, além de serem representações legítimas do passado, acabam por afetar a forma como vemos o passado. Isso se dá porque tais filmes, além de carregarem uma narrativa sobre um evento do passado, permitem ao espectador experimentar algumas "sensações" sobre um determinado fato histórico. Afirma o autor,

\begin{abstract}
Concentrando-se em pessoas documentadas ou criando personagens ficcionais que são colocados no meio de um importante acontecimento ou movimento (a maioria dos filmes contém tanto personagens reais quanto inventados), o pensamento histórico envolvido nos dramas comerciais é, em grande parte, o mesmo: indivíduos (um, dois ou um pequeno grupo) estão no centro do processo histórico. Através de seus olhos e vidas, aventuras e amores, vemos greves, invasões, revoluções, ditaduras, conflitos étnicos, experiências científicas, batalhas jurídicas, movimentos políticos, genocídios. Mas fazemos mais do que apenas ver: também sentimos. "Usando imagem, música e efeitos sonoros, além de diálogos falados (e berrados, sussurrados, cantarolados e cochichados), o filme dramático mira diretamente nas emoções" (Rosenstone, 1995, p. 13).
\end{abstract}

Ao defender que os filmes criam um "universo histórico" que também se dá no

\footnotetext{
${ }^{11}$ Acreditamos que um dos exemplos de filme que R. Rosenstone se refere pode ser a obra "Nós que aqui estamos por vós esperamos" do diretor brasileiro Marcelo Masagão, onde narra eventos históricos do século XX, através de imagens e histórias pessoais.
} 
campo emotivo, Rosenstone acredita que os mesmos marcam os espectadores não somente por seu conteúdo histórico, mas também pelas condições emotivas criadas a partir dos efeitos de montagem/trucagem e efeitos sonoros (trilha musical e sons ambientes). Dessa forma, o filme acaba por criar uma imagem sobre o passado mais sensível (no campo dos sentidos) que o texto histórico. Essa experiência não pode ser desprezada pelo historiador, apesar de o autor não especificar como tal experiência pode ser acessada.

\section{Considerações finais}

Dado o fato da presença do cinema hollywoodiano ter se acentuado em nossa cultura midiática e se é cada vez mais importante aprender como ler e criticar essa cultura, ao invés de evitar o uso desses materiais em nossas aulas de História, acreditamos que seu uso possibilite transcender a mensagem imediata da fábula (a história que o filme conta) para chegar aos temas a serem discutidos com o uso dos filmes no ensino: quais as condições de produção do filme? Sob qual contexto histórico ele foi produzido e que fatos podem ser percebidos em sua narrativa? Quais as questões ideológicas presentes no filme ou seu uso?

Considerando, ainda, que grande parte das produções cinematográficas estadunidenses têm no público jovem seu principal espectador e consumidor e, visto serem os adolescentes e jovens majoritariamente os estudantes com quem os professores de História trabalham na atualidade, os filmes hollywoodianos em sala de aula podem também nos auxiliar a compreender melhor as pessoas com as quais estamos trabalhando. Por isso considerarmos uma cultura da mídia não restrita a análise do material midiático, mas também pelos modos como as juventudes de estudantes hoje se relacionam com essas mídias. Nesse sentido o uso de filmes nas aulas de história podem nos auxiliar na construção de uma cultura crítica onde os estudantes passem de uma posição por vezes restrita ao consumo ou difusão midiática para a de sujeitos com maior autonomia e capacidade de se relacionar com esse mundo de sons, imagens e interação.

Por fim, mas não menos importante, o uso dos filmes hollywoodianos em sala de aula deve nos lembrar da necessidade de diversificarmos a nossa cultura fílmica, 
como também a dos estudantes, procurando também filmes de diferentes culturas, idiomas, temáticas e narrativas. Conhecer produtos e aspectos das indústrias cinematográficas argentina, libanesa, indiana, europeia e de quantos lufares mais puder, amplia o universo das imagens sobre o mundo, seus sons e, principalmente, suas histórias.

\section{Referências bibliográficas}

ABUD, K. et. al. 2010. Ensino de História. São Paulo: Cengage Learning, 177p.

BAUDRILLARD, J. 1981. Simulacros e simulação. Lisboa: Relógio D’Água, 201p.

BENJAMIN, W. 1992. Sobre arte, técnica, linguagem e política. Lisboa: Relógio D’Água, $235 p$.

BERGAN, R. 2007. Guia Ilustrado de Cinema. Rio de Janeiro: Jorge Zahar, 512 p.

BITTENCOURT, C. 2011. Ensino de História: fundamentos e métodos. São Paulo, Cortez. 4a. ed. 408 p.

BORDWELL, D. 2004. O cinema clássico hollywoodiano: normas e princípios narrativos. in: RAMOS, F. P. Teoria contemporânea do cinema: documentários e narrativa ficcional. São Paulo: Editora Senac São Paulo.

CACCIA-BAVA, A. et. al. 2004. Jovens na América Latina. São Paulo: Escrituras Editora. DARNTON, R. 2014. Poesia e polícia: redes de comunicação na Paris do século XVIII. São Paulo: Companhia das Letras, 228p.

KELLNER, D. 2001. A cultura da mídia. Estudos culturais: identidade e política entre o moderno e o pós-moderno. Bauru: EDUSC, 306p.

MORIN, E. 2011. La vía para el futuro de la humanidad. Barcelona: Espasa Libros, 297p. NAPOLITANO, M. 2004. Como usar o cinema na sala de aula. São Paulo: Contexto, $251 p$.

PAIS, J. M. 1993. Culturas juvenis. Lisboa: Imprensa Nacional Casa da Moeda.

REGUILLO, R. 2007. Las culturas juveniles: un campo de estúdio; breve agenda para la discusión. in: UNESCO, MEC, ANPED. Juventude e contemporaneidade. Brasília. Disponível em:

http://portal.mec.gov.br/index.php?option=com_docman\&view=download\&alias=648 -vol16juvcont-elet-pdf\&category_slug=documentos-pdf\&ltemid=30192. Acesso em 
$16 / 08 / 2016$

ROSENSTONE, R. A. 1995. Revisioning History. Film and the construction of a new past. New Jersey: Princeton University Press.

SHORT, K. R. M. (org). 1981. Feature films as History. Tennessee: University of Tennessee Press.

SCHATZ, T. 19910 gênio do sistema: a era dos estúdios em Hollywood. São Paulo:

Companhia das Letras, 396p.

SILVA, T. G. 2014. Dirigido por Martin Scorsese: um estudo comparativo de Taxi Driver, Os Infiltrados e seus contextos de produção. Rio de Janeiro, RJ, Dissertação de Mestrado, Universidade Federal do Rio de Janeiro. 212p.

SORLIN, P. 1998. The cinema: american weapon for the cold War. In: BOTTOMORE, S. (editor). Film History. New Jersey. Volume 10, 375-381 p.

TROVÃO, Flávio. 2015. Os filmes na escola: como trabalhar com o cinema na educação básica. em: ALVES, F. et. Al. Desenvolvimento da educação básica: desafios contemporâneos. Curitiba: Editora CRV, p. 71-84.

Artigo recebido em 03 de novembro de 2016 e aprovado em 28 de junho de 2017. 